FINAL REPORT

PROJECT NO. US-2809-96

Interploid Hybridization of Cucumis melo and c. metuliferus

J. Adelberg, H. Skorupska, W.B. Rhodes, Y. Cohen, R. Perl-Treves 
Date: $12-29-99$

BARD Project Number: US 2809-96R

Project Title:

Interpbid Hybridization of Cecum's trelo

- and C metuliferus

y

Investigators:

(Principal first)

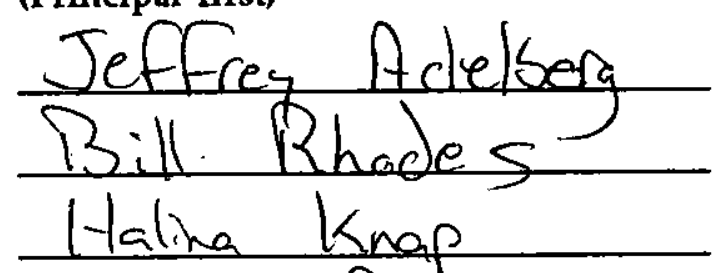

Rafael Perl Trees

Yiget Cohen

Project Start Date:

Type of Report: Mst Annual

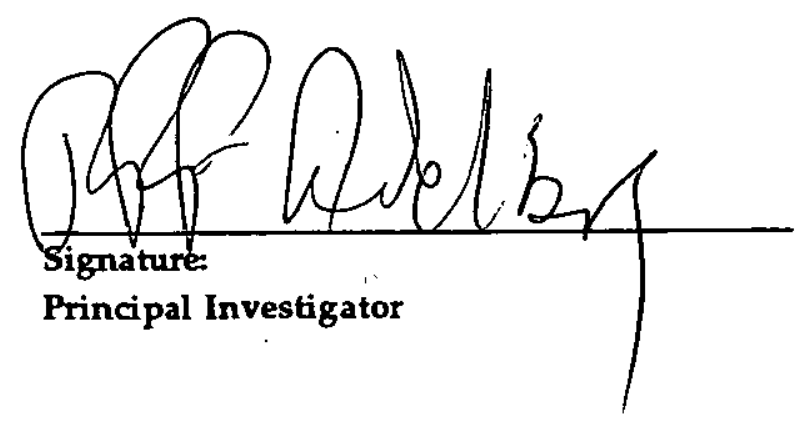

48

Appendix 6
Affiliated Institution:

Clemson University

Bar Iran University

and Annual

Final

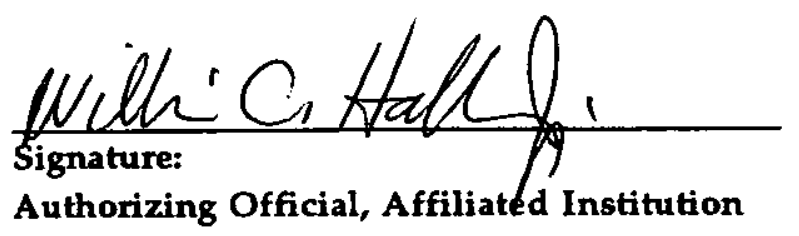

$\mathrm{DECE}, T \mathrm{D}$

sin 068 800

SF ST. PRO: :TE
AND ADMIN :TRON 

Interploid Hybridization of Cucumis melo and C. metuliferus
Abstract
Objectives of the original project
Data, methods, results and discussion
Description of the Cooperation
Evaluation of Achievement
9
List of Publications 


\title{
Interploid Hybridization of Cucumis melo and $C$. metuliferus
}

\begin{abstract}
The long-term motivation for this research is to transfer useful traits from a broad based gene pool of wild species into the narrow base of a cultivated crop in Cucumis. Our primary focus was to use polyploidy prior to fertilization as a tool to overcome fertility barriers in the cross between $C$. melo and $C$. metuliferus. In conducting this research, we explored all combinations of tetraploid and diploid parents, in reciprocal combinations. Pollinations were made in both the field and greenhouse, using emasculated flowers, moneocious females, and open pollination by insect vectores, with morphological selection criteria. After observations of thousands of ovaries, we still have no definitive proof that this hybridization yielded viable embryos. The most promising results came from using tetraploid $C$. metuliferus, as the maternal parent in the interspecific hybridization, that set fruit where seeds contained small embryos that did not germinate. To obtain fruit set, it was important to rear plants in a cooler sunny greenhouse, as would was found in late winter/early spring.
\end{abstract}

A second interspecific hybrid between wild and cultivated Cucumis, C. hystrix $x$ C. sativus, yielded fertile progeny for the first time, while concomitantly working toward our primary goal. Two distinct treatments were necessary; 1) special plant husbandry was necessary to have the wild species produce fruit in cultivation, and 2) embryo rescue followed by chromosome doubling in vitro was required for fertility restoration. Backcrosses to crop species and resistance to nematodes are compelling areas for further work. 


\section{Objectives of the original project}

The primary objective of the original project was to use polyploidy as a bridge mechanism for overcoming incompatibility in interspecific hybridization of two Cucumis species, $C$. melo and $C$. metuliferus. The second objective, contingent on success of the first, was to use molecular markers to confirm hybridization and describe chromosome number and fertility of hybrid progeny.

In the second crop season of the 18 month project, we added a second cross in Cucumis, the cultivatedC. Sativus, and a wild species $C$. hysrtrix, where we were able to make substantial progress.

\section{Data, methods, results and discussion}

We have spent the past two cropping seasons working toward interspecific hybridization between $C$. melo and C. metuliferus, utilizing germplasm at different ploidy levels. Much interesting information has been obtained, but we could not make a viable hybrid. During the end of this grant we were able to pursue another interspecific hybrid in Cucumis, and restore fertility by doubling the chromosomes of the hybrid. This activity will be summarized as part of this report.

\section{Synchronizing flowering time between C. melo and C. metuliferus}

If grown from transplant in April under conventional outdoor field conditions, $C$. metuliferus will not flower until late August and September, when C. melo is no longer able to set fruit. Tetraploid of $C$. metuliferus prepared for this project had similar flowering requirements as diploid. By starting transplants in greenhouse in February, both species flower simultaneously in May. When C. metuliferus are started as transplants in 
April in a short-day regime growth chamber, flowering plants can be brought to the field (Table 1) and was used to pollinate $C$. melo in field in July.

Table 1. Days from germination ( \pm standard error) to flower for $C$. metuliferus when plants were grown in greenhouse in April and May, or short-day (8 hour) growth chamber for 28 days in April before being brought to greenhouse.

\begin{tabular}{lcccc}
\hline & \multicolumn{2}{c}{ Short-day treatment } & \multicolumn{2}{c}{ Natural day length } \\
& male flowers & female flowers & male flowers $:$ & female flowers \\
diploid & $48.6 \pm 0.5$ & $49.0 \pm 0.5$ & $>56$ & $>56$ \\
tetraploid & $49.1 \pm 0.6$ & $46.4 \pm 0.3$ & $>56$ & $>56$ \\
\hline
\end{tabular}

Controlled pollination of $4 \times$ C. metuliferus in greenhouse (summer 1997)

Tetraploid $C$. metuliferus (with monoecious flower) was used as a female for interspecific hybridization in the greenhouse. Hundreds of pollinations resulted in a few fruit set. Fruit set occurred in early season and with 'Ogen' as pollen parent (Table 2). Small seed was found in the fruit sac, with heart shaped opaque bodies at the micropylar end presumed to be embryo (Fig. 1). Growth regulator combinations $(0,0.1,1,10 \mu \mathrm{M}$ NAA x $0,0.1,1$, $10 \mu \mathrm{M}$ BA ) were attempted on agar and liquid systems but there was no regeneration, and only sporadic callus development.

Table 2. Numbers of fruit set when tetraploid C. metuliferus was hybridized in the greenhouse with a variety of $C$. melo sources. 


\begin{tabular}{lcccc}
\hline Pollen parent & \multicolumn{2}{l}{ \# of pollinations (June) } & \# of pollinations (July-October) \\
\cline { 2 - 4 } & Fruit set & Abortive ovaries & Fruit set & : Abortive ovaries \\
'Ogen' & 2 & 1 & 0 & 500 \\
'Green Ice' & 1 & 1 & 0 & 33 \\
'Rocky Ford' & 0 & 3 & 0 & 30 \\
'virescent' 4x & & & 0 & 53 \\
\hline
\end{tabular}

Modified open-pollination of $4 \times$ C. melo /virescent by C. metuliferus (summer 1997)

The recessive virescent marker in tetraploid C. melo was present in a breeding line where it segregated for monoecious flowering (21 mono: 27 andromonoecious plants). For five weeks, interspecific hand pollinations with diploid C. metuliferus were attempted on 491 monoecious and 233 emmasculated andromonoecious flowers, resulted in 0 fruit set. After that time, efforts were made to remove all male flowers from the tetraploid melon, and native bee populations were allowed to perform the pollination, knowing the recessive, albino cotyledon-hypocotyl maker would distinguish self-pollinations. Fourty-one fruit set on monoecious and 25 fruit set on andromonoecious plants under these conditions. All fruits from this field were surface sterilized and seeds were harvested under aseptic conditions. Seed were separated into three categories, (1) normal seed with embryos filling seed coat, (2) abnormal seed, partially hardened seed coat with small embryos (Fig 2.), and (3) empty seed without visible embryos in seed coat (Table 3). It was assumed that interspecific fertilization may result in abnormal embryos, and those abnormal seed were placed in aseptic culture.

Analysis of progeny from the embryos produced by native bee pollinations in the field containing C. metuliferus in flower are as follows: The 1442 normally-filled seed 
from tetraploid virescant monoeocious plants were germinated yielding 1380 seedlings, all were albino (Fig. 3). From 1852 filled seeds of andromonoecious, 1700 germinated, all were albino. Since $100 \%$ of the seedlings were albino, the normally-filled seed were derived from self-pollination. From the small embryos of abnormal seed from more than 60 fruits, over 300 tissue culture lines were derived. 150 regenerants were flowered in the greenhouse where $100 \%$ showed the white flower marker, pleiotropic with albino traits of virescent cotyledon/hypocotyl. This indicated abnormal embryos were also from selfpollination.

Table 3. Numbers of seed produced during open pollination of tetraploid virescent melon, with male flowers removed, while interplanted diploid $C$. metuliferus was flowering in the field 1997. Seed were classified by size of embryos.

\begin{tabular}{|c|c|c|c|c|c|}
\hline flower type & \# of fruit & \# of seed & full embryo & abnormal seed & empty seed \\
\hline andromon. & 25 & 3368 & 1852 & 317 & 1199 \\
\hline monoecious & 47 & 3317 & 1442 & 431 & 1444 \\
\hline
\end{tabular}

\section{Controlled Pollination in Greenhouse, Spring 1998}

Pollinations of tetraploid $C$. metuliferus proceeded in the greenhouse in the Spring of 1998 using pollen from eleven genotypes of melon (Ogen-2n and 4n, Green Ice-2n and 4n, Rock Ford Green-4n, Rocky Ford Green x Ogen- 2n and 4n, Green Ice x Ogen-2n and $4 n$, Ogen $x$ Green Ice- $2 n$ and $4 n$ ). Dozens of fruit set without (preference for pollen source) during the long days of April and May, before the heat. Viable embryos were tissue cultured but all progeny resembled C. metuliferus, without any traits of C. melo. This material was discarded as inadvertent self-pollination. 
Pollinations of tetraploid melon with pollen from tetraploid $C$. metuliferus resulted in very few fruit set. Seed were not viable and embryos were not recovered in tissue culture.

\section{Field Pollination, Summer 1998}

Diploid and tetraploid C. metuliferus were germinated in short day growth chambers and transplanted at time of flower to 4 liter nursery pots. Two hundred of these pots were set in field at $2 \mathrm{~m}$ spacing (Diploids on east side of field tetraploid on west, with four rows of watermelon separating them). Transplants of mixed F4 and F5 melon populations of $4 \mathrm{n}$ and semi-fertile $3 \mathrm{n}$ melon were interplanted with both diploid and tetraploid C. metuliferus in mid- May. Hundreds of perfect flowers of polyploid melon were emasculated and hand pollinated with either diploid or tetraploid C. metuliferus. Fruit failed to set. By the end of July, emasculation was discontinued. All male flowers were removed from melon, and native bees were permitted to pollinate the melon flowers. Careful observation of bee movement confirmed bees were visiting both $C$. metuliferus and C. melo on the same journey. Approximately 50 fruit set on the polyplivid melon, interplanted with both diploid and tetraploid sides of field. Thousands of seed were harvested, cleaned, germinated and evaluated in the greenhouse in the fall. Seedlings with odd-shaped leaves were observed and grown to maturity. All produced fruit that were characteristic of melon. The odd vegetative morphology was likely to have been caused by aneuploidy of self-pollinated melons from perfect flowers on andromonoecious vines.

\section{In vitro biology}

Regeneration systems from immature embryos of Cucumis was included as an "off-season" activity for some of our staff. The practical importance of having the most 
updated knowledge on embryo-rescue and chromosome doubling was required. Since, genotypic variation is a widely reported to be such an important variable in success of this type of work, we conducted a thorough study on regeneration systems for melon involving genotypes included in this study. One short manuscript appeared in the proceedings of the "Plant Biotechnology and In Vitro Biology for the $21^{\text {st }}$ Century", that was held in Jerusalem, 1998 (A copy of is attached). Other work in awaits further data analysis.

Additional work conducted with $\mathrm{C}$. hystrix and $\mathrm{C}$. sativus.

A second interspecific hybrid received much attention during the latter part of this grant. Cucumber (C. sativus $\mathrm{n}=7$ ) has been hybridized with $C$. hystrir. $(\mathrm{n}=12)$. This work was originally done by JF Chen at Saga University in Japan resulted in I sterile hybrid with $\mathrm{n}=19$ that never set fruit. While in Clemson working on this grant, we were able to make several substantial steps to progress work with this hybrid. A paper was delivered at Cucurbitaceae '98, on this subject and copies are attached. A feature article for HortScience will be published in February, 2000.

1. C. hystrix was brought to female flower under cultivated conditions, previously this had not been possible.

2. Interspecific hybrids were made with either species as female parent.

3. Chromosome doubling was accomplished in vitro, as part of embryo rescue procedure.

4. Sterile hybrids from $C$. hystrix as female parent set large amounts of seedless fruit when allowed to open pollinate in the presence of C. sativus.

5. Tetraploid hybrids from C. hystrix as female parent, only, produced fertile progeny when self pollinated or backcrossed to C. sativus. 
6. C. hystrix, the tetraploid and the backcross progeny have resistance to root knot nematode at higher levels than the crop species, $C$. sativus.

\section{Description of the Cooperation}

Dr. Cohen's group had worked in the greenhouse using the virescent male sterile germplasm developed previously in the USDA program. Despite good cultural conditions, this germplasm was found to be highly female sterile, and of no practical use for interspecific crosses. The other tetraploid melon lines, produced seed sporadically upon self-pollination and had no ability to hold fruit following interspecific crosses.

Dr. Perl-Treves developed markers to distinguish melon and tetraploid metuliferus lines used in this project. He also developed markers for a variety of otiner tetraploid melon germplasm in this project, but unfortunatley had no occasion to test thetn on putative progeny.

Information was exchanged during Adelberg's visit to Israel in șummer 1998. Successes with $C$. sativus and $C$. hystrix were shared with Israeli group. Focus of the project was shifted toward submitting a proposal for work on this second cross. This proposal was submitted jointly in September 1998.

\section{Evaluation of Achievement}

Using polyploidy as a tool to for overcoming barriers to interpsecific hybridization in Cucumis spp. is a valid approach. Unfortunately the cross we originally selected, involving $C$. melo and $C$. metuliferus remains ellusive. The idea of using tetraploid parents prior to fertilization did not result in embryos that were viable for germination or rescue.

The second cross we described with $C$. hystrix and $C$. sativus was successful, but requires a few special skills. C. hystrix must be the female parent. It was grown for more than six months, and was moved in large pots to the field before it would flower. Embryos 
extracted from cucumber hybridized with $C$. hystrix produce both diploid and tetraploid regenerants. Both ploidy levels are male and female sterile. When $C$. hystrix is female parent, the embryo rescue also yields regenerants of both ploidy levels. The diploid interspecific hybrid of this reciprocal cross will set parthenocarpic fruit when pollinated with cucumber. The tetraploid interspecific hybrid is both self-fertile and can be backcrossed to cucumber. Some modest degree of nematode resistance may be transmitted by this cross.

\section{List of Publications}

Adelberg and Chen. 1999. Genetic control of regeneration was altered during one-week ripening of immature cotyledons on liquid/membrane system. Pgs. 21-25. In: A. Altman, M. Ziv, and S. Izhar (ed.), Plant Biotechnology and In vitro Biology in $21^{\text {st }}$ Centrury, Kluwer Academic Publishers, Dordecht, Netherlands.

Chen, J.F., J. W. Adelberg, J. E. Staub, H. T. Knap, and B. B. Rhodes. 1998. A new synthetic amphidiploid in Cucumis from a C. sativus $x$ C. hystrix F1 Hybrid. Pg. 336-339. In J.D. McCreight (ed.), Proceedings of Cucurbitaceae '98, ASHS Press.

Chen, J.F and J.W. Adelberg. Interspecific hybridization in Cucumis-progress, problems and perspective (in press, HortScience - cover article) 
